\title{
BMJ Open High adherence to the 'Wise List' treatment recommendations in Stockholm: a 15-year retrospective review of a multifaceted approach promoting rational use of medicines
}

Jaran Eriksen, ${ }^{1,2}$ Lars L Gustafsson, ${ }^{1,2}$ Kristina Ateva, ${ }^{3}$ Pia Bastholm-Rahmner, ${ }^{4}$ Marie-Louise Ovesjö, ${ }^{1,5}$ Malena Jirlow, ${ }^{6}$ Maria Juhasz-Haverinen, ${ }^{6}$ Gerd Lärfars, ${ }^{7}$ Rickard E Malmström, ${ }^{1,8}$ Björn Wettermark, ${ }^{1}$ Eva Andersén-Karlsson ${ }^{7}$

To cite: Eriksen J,

Gustafsson LL, Ateva K, et al. High adherence to the 'Wise

List' treatment

recommendations in

Stockholm: a 15-year retrospective review of a multifaceted approach promoting rational use of medicines. BMJ Open 2017;7:e014345. doi:10.1136/bmjopen-2016014345

- Prepublication history for this paper is available online. To view these files please visit the journal online (http://dx.doi.org/10.1136/ bmjopen-2016-014345).

Received 5 October 2016 Revised 26 January 2017 Accepted 13 February 2017

CrossMark

For numbered affiliations see end of article.

Correspondence to Dr Jaran Eriksen; jaran.eriksen@ki.se

\section{ABSTRACT}

Objectives: To present the 'Wise List' (a formulary of essential medicines for primary and specialised care in Stockholm Healthcare Region) and assess adherence to the recommendations over a 15-year period.

Design: Retrospective analysis of all prescription data in the Stockholm Healthcare Region between 2000 and 2015 in relation to the Wise List recommendations during the same time period.

Setting: All outpatient care in the Stockholm Healthcare Region.

Participants: All prescribers in the Stockholm Healthcare Region.

Main outcome measures: The number of core and complementary substances included in the Wise List, the adherence to recommendations by Anatomic Therapeutic Chemical (ATC) 1st level using defined daily doses (DDDs) adjusted to the DDD for 2015, adherence to recommendations over time measured by dispensed prescriptions yearly between 2002 and 2015.

Results: The number of recommended core substances was stable (175-212). Overall adherence to the recommendations for core medicines for all prescribers increased from $75 \%$ to $84 \%$ (2000 to 2015). The adherence to recommendations in primary care for core medicines increased from $80 \%$ to $90 \%$ (2005 to 2015) with decreasing range in practice variation (32\% to 13\%). Hospital prescriber adherence to core medicine recommendations was stable but increased for the combination core and complementary medicines from $77 \%$ to $88 \%$ (2007 to 2015).

Adherence varied between the 4 therapeutic areas studied.

Conclusions: High and increasing adherence to the Wise List recommendations was seen for all prescriber categories. The transparent process for developing recommendations involving respected experts and clinicians using strict criteria for handling potential conflicts of interests, feedback to prescribers, continuous medical education and financial incentives

\section{Strengths and limitations of this study}

- The study data cover all prescriptions for the Stockholm Healthcare Region (population 2.2 million).

- The study includes all care providers in the Stockholm Healthcare Region.

- The study does not include a control group.

- A causal relationship between the guidelines and the seemingly high adherence cannot be determined.

are possible contributing factors. High-quality evidence-based recommendations to prescribers, such as the Wise List, disseminated through a multifaceted approach, will become increasingly important and should be developed further to include recommendations and introduction protocols for new expensive medicines.

\section{BACKGROUND}

Inappropriate use of medicines increases the risk of therapeutic failure, adverse events, antimicrobial resistance and is a waste of resources. $^{1-6}$ This recognition was a driving force behind the establishment of Drug and Therapeutics Committees (DTCs) ${ }^{7-9}$ and the Essential Medicines concept ${ }^{10}$ introduced by the WHO in the 1970s. DTCs select medicines based on scientific evidence and influence physician prescribing to achieve rational use of medicines (RUM). ${ }^{8} \quad 10 \quad 11$ As part of their strategies, DTCs develop treatment guidelines and formularies but changing behaviour takes time and adherence to recommendations varies among prescribers and is surprisingly poor in most cases. ${ }^{12} 13$ 
Consequently, new models need to be developed and evaluated to provide trust and adherence to recommendations of essential medicines throughout the healthcare system.

In 1996, a new Swedish law stipulated that each healthcare region should have at least one DTC to issue guidelines/recommendations and promote RUM. ${ }^{8}$ This law has been essential as a platform and base for gaining trust in and assuring resources for DTCs in Stockholm. Six years after introduction of the law, medicines budgets were devolved from the national to the regional level. ${ }^{14}$ These changes prompted new ways to communicate independent prescribing recommendations such as the 'Wise List' concept of essential medicines for common diseases introduced in Stockholm (box 1). ${ }^{15}$ The concept was designed based on the understanding that prescribing recommendations should be issued in one version for the whole region irrespective of whether patients were treated in primary or in specialised care in public or private facilities. Furthermore, a key consideration was that the recommendations have to be based on evidence and should be issued jointly by respected experts and clinicians with an aim to enhance quality of care. ${ }^{8}{ }^{11}{ }^{15-18}$ The Wise List concept was developed knowing that multifaceted contextualised methods are needed to implement recommendations. Such strategies

\section{Box 1 The Wise List concept ${ }^{20}$}

- The Wise List ('Kloka Listan' in Swedish) was developed for the whole Stockholm Healthcare Region in 2000 (the name 'Wise List' was launched in 2001)

- Includes around 200 recommended core medicines for the treatment of common diseases in primary and hospital care

- Includes 100 complementary medicines for common diseases in specialised care (since 2007)

- Covers 24 therapeutic areas

- Is a pocket-sized booklet and also available in a web-version

- Respected experts and clinicians together with clinical pharmacologists, pharmacists and nurses agree on recommendations based on review of scientific evidence using transparent criteria, including cost-effectiveness evaluation

- Is a joint effort across disciplines and institutions and includes a policy for conflict of interest with annually renewed declarations. This policy contains rules and regulations for definitions of conflict of interest and how to handle them ${ }^{25}$

- Includes non-pharmacological advice for several therapeutic areas. For some therapeutic areas, there are stepwise recommendations linked to disease severity and concomitant diseases.

- The Wise List also includes around 10 'Wise piece of advice' (short, focused messages) selected yearly to improve certain pharmacotherapeutic practices for which there are potential for improvement in quality of medicine use, for example, 'Do not treat uncomplicated acute bronchitis with antibiotics'

- The Wise List is communicated through a comprehensive communication, branding and marketing strategy with experts in a key role and integrated with a programme for continuous medical education ${ }^{15} 18$ (Box 2) may include professional ownership, continuous medical education, active dissemination, 'point-of-care' access to independent information about medicines as well as feedback of prescribing patterns to physicians using modern Information Communication Technology (ICT). ${ }^{17} 19$ These concepts were all applied in what was introduced as the 'Stockholm Model for Wise Use of Medicines' (box 2). The Stockholm Healthcare Region had five local DTCs with their own formularies from 1980s to 1999, but a joint formulary for the entire Stockholm Healthcare Region was first issued by the regional coordinating DTC in $2000 .^{15}$ The Wise List concept has since then continuously improved to reach a mature design and work process. In 2008, a minor financial incentive was introduced for primary healthcare centres (PHCs) meeting agreed prescribing targets and writing an annual quality report. ${ }^{14}$ Since its launch, the Wise Lxist concept has been further refined to address the increasing challenge to manage the introduction of new expensive medicines as well as to reduce the negative environmental impact of medicines. ${ }^{20}$

Owing to increasing costs for developing medicines, generic competition and the strained global healthcare budgets, pharmaceutical companies have changed their

\section{Box 2 The Stockholm model for wise use of medicines}

The core part of the model is The Wise List. The outer circle represents the Key Strategies and the Organisational Unit, which are a prerequisite for the collaborative work for a rational use of medicines. Since 1996, a new Swedish law stipulated that each healthcare region should have at least one Drug and Therapeutics Committee (DTC). This has provided mandate and organisational stability to issued recommendations by DTCs. ${ }^{8}$ The jigsaw puzzle shows key elements necessary for producing the Wise List and implementing its guidelines in medical practice in the Stockholm Healthcare region. Operative resources include an annual budget for staff, continuous medical education of our 200 experts, infrastructure, printing, distribution and marketing of the Wise List.

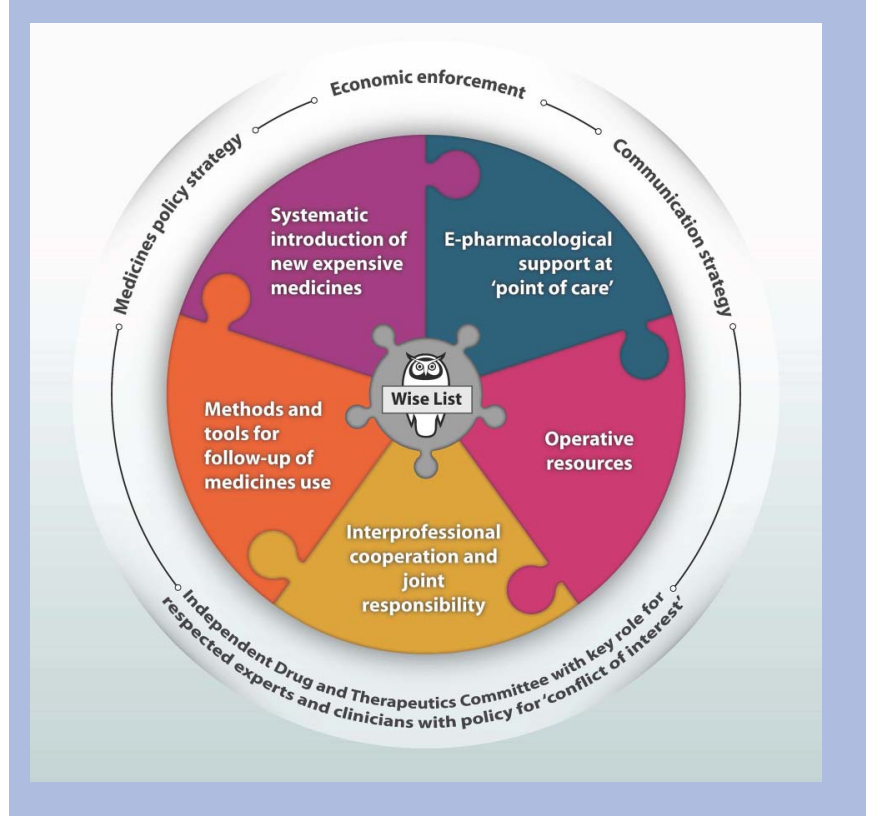


focus from blockbuster medicines to niched orphan drugs that have a potential to generate more revenue. ${ }^{21}$ At the same time, there is growing evidence that the pharmaceutical industry influences prescriber practices, ${ }^{22}{ }^{23}$ but healthcare funders and medical professionals are increasingly implementing measures to minimise negative consequences of this. ${ }^{24}$ In the context of the changing medicines market, the need for independent, evidence-based information for prescribers becomes increasingly important. To the best of our knowledge, there have been no scientific evaluations of health system-wide interventions aiming to tackle this challenge. It is therefore important to evaluate the effects of such work performed to further refine strategies for optimising use of medicines. The objective of this paper is to describe the content of the 'Wise List' since its launch and to assess prescribers' adherence to the recommendations over a 15 -year period.

\section{Definitions used in this paper}

Core medicines: Essential medicines for common illnesses, recommended for primary and specialised care.

Complementary medicines: Additional essential medicines to be recommended primarily for specialised care.

These definitions are based on the WHO model list of essential medicines. ${ }^{26}$

\section{MATERIALS AND METHODS \\ Study area}

This study was conducted in Stockholm Healthcare Region with $\sim 2.2$ million inhabitants served by more than 200 PHCs, 7 emergency hospitals as well as geriatric clinics, psychiatric services, private specialists, nursing homes and other healthcare providers (eg, occupational health, school health and rehabilitation). Swedish healthcare is financed through public taxation with limited patient copayment for prescribed medicines and healthcare visits. ${ }^{27}$

\section{Data sources}

The number of different substances recommended as core or complementary medicines was collected from a database of the contents of the 'Wise List' from 2000 to 2015. Data are presented by therapeutic area ATC 1st level and year. ${ }^{28}$ The year 2000 was chosen as the initial year of observation as the first joint list of recommendations for the whole region was launched that year.

We also compiled all 'Wise pieces of advice' (short messages aimed at improving pharmacotherapy (box 1, table 1)), from each edition of the 'Wise List'.

Data on dispensed prescriptions were collected from the Swedish Prescribed Drug Register. In addition to the prescriptions, the register contains patient demographics (age, sex and area of residence of the patient) as well as information about the unit where the prescription was issued. ${ }^{29}$

\section{Data analysis}

Number of substances and the Wise pieces of advice

The number of substances included in the Wise List each year was calculated and presented according to their classification as core or complementary medicines.

The Wise pieces of advice were grouped within four areas, that is, (1) choice of medicine-that is, preferred choice of substance within a group of medicines used for a specific disease, (2) overtreatment-that is, avoid using medicines unnecessarily, (3) undertreatmentthat is, reminders to test for and treat conditions that are underdiagnosed and/or undertreated in the Stockholm region or (4) any other type of general advice related to RUM.

Table 1 Some examples of the 55 individual Wise pieces of advice included in the Wise List

Example of advice

Use naproxen as first choice when prescribing COX inhibitors

Choose simvastatin for prevention of cardiovascular disease in high-risk patients with normal to medium increased levels of cholesterol

Do not use quinolones for treatment of uncomplicated urinary tract infection (UTI) in women Always give the patient an updated medication list

Estimate and consider renal function in the selection and dosing of medicines

Verify the diagnosis before treating according to the 'heart failure treatment ladder' and seek to establish good heart rate control (below 70 bpm in sinus rhythm)

Do not treat uncomplicated acute bronchitis with antibiotics

Do not treat asymptomatic bacteriuria in the elderly and only culture from urine if the patient is experiencing urinary tract symptoms

Treatment with proton pump inhibitors is not advisable in the case of stomach pain of unknown cause Improve antihypertensive treatment: determine a target blood pressure together with the patient, combine medicines more often and follow-up

Treat depression to complete remission

Increase the use of medicines to prevent relapse in alcohol dependence and follow-up treatment outcome

Categories: (1) choice of medicine- that is, preferred choice of substance within a group of medicines used for a specific diagnosis, (2) overtreatment - that is, avoid using medicines unnecessarily, (3) undertreatment-that is, reminders to look for and treat conditions that are often inadequately diagnosed and/or treated or (4) any other type of general advice related to drug therapy.
Category of advice Choice of medicine Choice of medicine

Choice of medicine General advice General advice General advice

Overtreatment Overtreatment

Overtreatment Undertreatment

Undertreatment Undertreatment 


\section{Adherence to recommendations}

Data were analysed by ATC using defined daily doses (DDDs) adjusted to correspond to the DDD for the year $2015 .^{28} 30$ The year 2002 was chosen as baseline since a national regulation for mandatory generic substitution resulting in substantial price reductions for generics was introduced in October that year, thus changing the pharmaceutical market substantially. ${ }^{14} 31$ Separate analyses on the overall adherence were also made for each individual PHC in 2005, 2010 and 2015 to assess to what extent variation between practices had changed over time.

Data on prescriptions were analysed with respect to the overall adherence to the Wise List recommendations -for all prescribers and by category (primary care, outpatient hospital care and others). The category others included psychiatry, geriatrics, rehabilitation, school health, occupational health and private practitioners of various specialities. Data on prescriber category were available from 2003.

\section{Change over time in adherence to recommendations}

Adherence to recommendations was measured based on all dispensed prescriptions in Stockholm Healthcare Region each year between 2000 (the year the first joint list of treatment recommendations in Stockholm was launched) and 2015. Adherence to guidelines in different pharmacotherapeutic areas were studied from 2002 (when prescriber work place ID was added to the Swedish Prescribed Drug Register, and a national regulation for mandatory generic substitution was introduced in Sweden) to 2015. We studied adherence to the guidelines in the following four different pharmacotherapeutic areas: (1) proton pump inhibitors (PPIs), (2) COX inhibitors, (3) statins and (4) selective serotonin receptor uptake inhibitors (SSRIs) or serotonin-norepinephrine reuptake inhibitors (SNRIs). These medicines were selected as there were specific 'Wise pieces of advice' relating to these groups of medicines during the study period. The Wise pieces of advice concerning these pharmacotherapeutic areas were warranted either because of safety concerns or because there was a need to counteract commercial pressure on physicians to prescribe new, less cost-effective treatments. ${ }^{32} 33$

\section{Statistical analyses}

Descriptive statistics were used including numbers and proportions expressed in percentages for different groups. The adherence to the Wise List was measured using the Drug Utilisation 90\% (DU 90\%) method. ${ }^{34}$ This method is recommended by the WHO for drug utilisation studies and defines the number of different substances (ATC 5th level) constituting 90\% of the volume expressed in DDDs and the adherence to recommendations within this segment. ${ }^{34}$ Note that the calculated adherence rate is not linked to data on diagnosis of the patient, but shows the amount of the substances prescribed for each specific ATC group of substances on the Wise List. For example, for ATC A02BC (PPI), if a substance recommended on the Wise List is prescribed, it is considered adherent to the Wise List recommendation. This method is routinely used in the Stockholm region to monitor the adherence to the Wise List recommendations as well as to provide feedback to prescribers forming the basis for local quality assessment and continuous medical education. ${ }^{19} 35$

Variation in adherence rates between practices was calculated using the extremal quotient (ratio of maximum to minimum value).

All data were analysed using the statistical package SAS V.9.4 (SAS Institute, Cary, North Carolina, USA) and Microsoft Excel 2010.

\section{Ethical considerations}

This work was based on routinely available aggregate prescribing information from databases used for monitoring healthcare with no possibility to identify individual patients or prescribers. The analyses were part of ongoing quality improvement work at Stockholm Healthcare Region. All data analyses complied with Swedish Personal Data Act and no application for approval by the Regional Institutional Review Board was therefore needed.

\section{RESULTS}

Number of substances included as recommendations in the Wise List over time

The number of recommended core medicines in the Wise List was relatively stable over the years, fluctuating between 175 and 212 substances. Complementary medicines were included in the Wise List from 2007 and have remained at around 100 substances since then (figure 1).

\section{Categories of Wise pieces of advice}

The concept of Wise pieces of advice was introduced in 2003. There have been around 10 individual pieces of advice every year, comprising in total 55 unique messages. Some advice were only included in the list for 1 year, whereas 20 of the advice have been included for 3 years or more. Most advice $(n=19)$ addressed choice of medicine within a class, the remaining concerned general advice $(n=14)$, overtreatment $(n=12)$ or undertreatment $(n=10)$. The pharmacotherapeutic areas with the highest number of Wise pieces of advice were cardiovascular diseases $(n=9)$, infectious diseases $(n=8)$, general/geriatric $(n=7)$, psychiatry and pain treatment (both $\mathrm{n}=7$ ). Examples of advice are listed in table 1 .

\section{Overall adherence to the Wise List}

The overall adherence to the Wise List recommendations for core medicines for all prescribers (primary and specialised care) in the region increased steadily from $75 \%$ in 2000 to $84 \%$ in 2015 . The adherence rates differed between prescriber categories, but increased for all of them. 
Figure 1 Number of substances included in the Stockholm Healthcare Region's Wise List over time. Core medicines, essential medicines for common illnesses, used in primary and hospital care. Complementary medicines, additional essential medicines to be used primarily for specialised care. $^{26}$

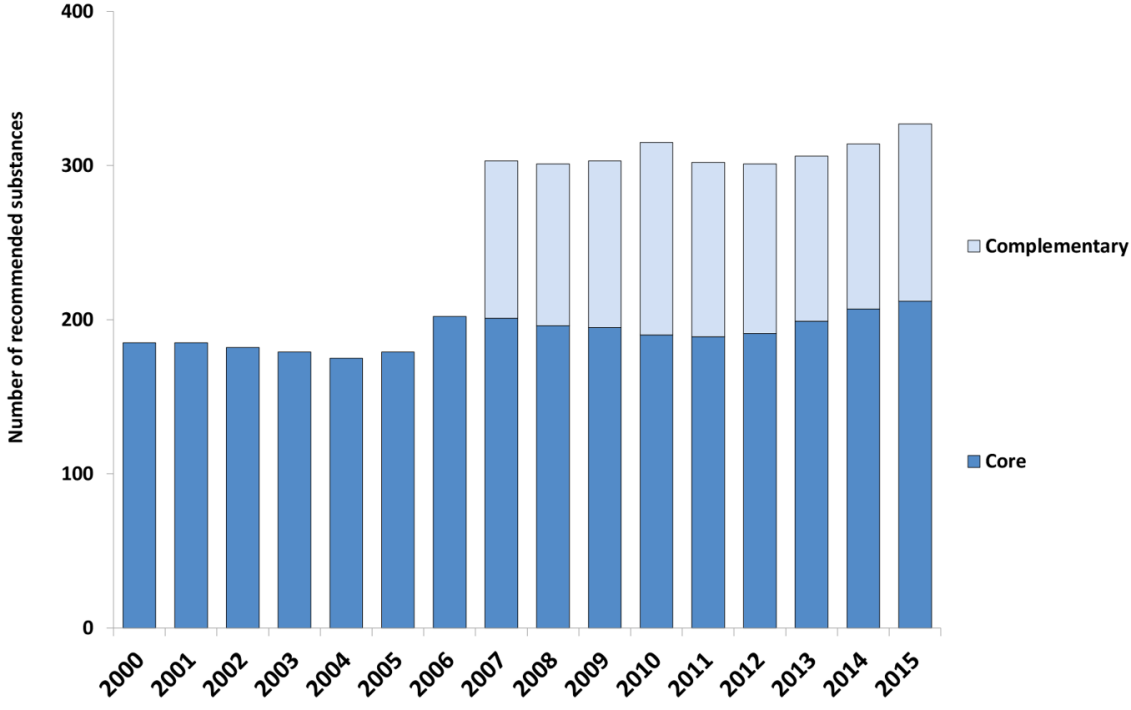

The adherence to recommendations in primary care for core medicines increased from $80 \%$ in 2005 to $90 \%$ in 2015 (figure 2) and showed a decreasing range in variation between practices over time from $32 \%(57 \%$ to $89 \%)$ in $2005,26 \%$ (69\% to $95 \%$ ) in 2010 to $13 \%$ (84\% to $97 \%$ ) in 2015 . The extremal quotient showed a significant reduction from 1.6 in 2005, 1.4 in 2010 to 1.3 in 2015.

For prescribers at hospitals, the adherence to core medicine recommendations was stable from 2003 to $2015(71 \%$ to $73 \%)$ but increased for the combination core plus complementary medicines between 2007 and 2015 from $77 \%$ to $88 \%$. For all other prescriber categories, the adherence increased over the time periods for core $(65-72 \%)$ and for the combination core plus complementary medicines (71-83\%) (figure 2).

\section{Adherence to specific pharmacotherapeutic areas in the Wise List \\ Statins}

Wise pieces of advice for statins have been included in the Wise List most years since its launch. The recommendation has been to increase the use of statins in high-risk patients, as well as to choose simvastatin. Simvastatin had good documentation and low price due to patent expiry already in 2003 and was, before patent expiry of atorvastatin, considered more cost-effective than the other statins. ${ }^{36}$ The volumes of statins increased throughout the period and simvastatin was the dominating substance. Prescribing of other statins remained at a low level but when the patent for atorvastatin expired and less expensive generics became available, the Wise List included this substance among the recommended ones (from 2013), which is also reflected in higher volumes of atorvastatin prescriptions dispensed (figure 3 ).

\section{Proton pump inhibitors}

There have been several Wise pieces of advice related to the use of PPIs in the Wise List over the study period. These have aimed to decrease unnecessary use of PPIs, as well as recommending omeprazole (and pantoprazole and lansoprazole in 2002-2003) instead of other less costeffective PPIs. Despite this, volumes of PPIs more than
Figure 2 Adherence to recommendations (DU90\%) in the Wise List for different prescriber categories in Stockholm Healthcare Region between 2003 and 2015. Data on complementary medicines available only from 2007. 'Others' includes psychiatry, geriatrics, rehabilitation, school health, occupational health and private practitioners in various specialties.
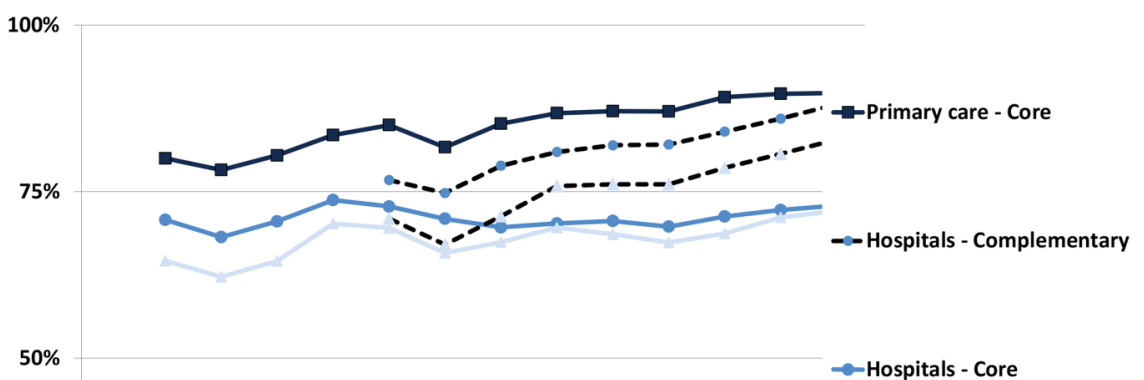

$25 \%$

$0 \%$

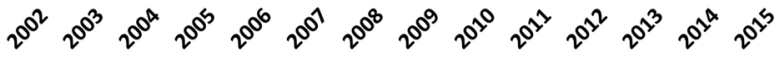


Figure 3 Prescribing patterns for statins in Stockholm Healthcare Region between 2002 and 2015 showing all statin prescriptions dispensed to the inhabitants in the region each year. The letter ' $R$ ' signifies that the drug was a core recommendation in the Wise List that year. DDD/TID, defined daily dose/1000 inhabitants/day.

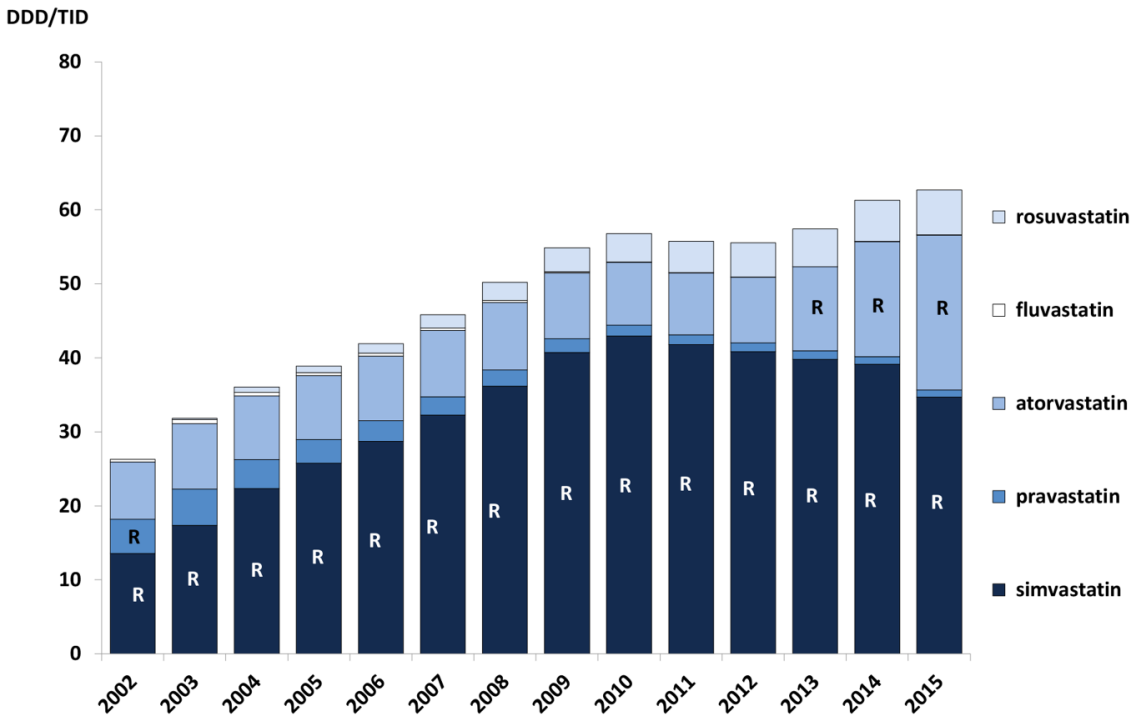

doubled between 2002 and 2015 to the equivalent of $4.5 \%$ of the population constantly treated with PPIs with the vast majority of prescriptions for omeprazole (figure 4).

\section{Serotonin receptor uptake inhibitor/serotonin-norepinephrine reuptake inhibitor}

Owing to strong marketing pressure from the industry to prescribe the S-enantiomer of citalopram (escitalopram), ${ }^{37}$ a Wise piece of advice was introduced in 2011 recommending the prescriber to use either citalopram or sertraline for patients in need of pharmacological treatment of depression. Citalopram and sertraline dominated the treatment throughout the period, but prescriptions for all other antidepressants have also increased (figure 5).

\section{COX inhibitors}

In 2012, the Wise List changed its recommendation from diclofenac to naproxen based on accumulated evidence indicating an increased risk for cardiovascular events in patients using diclofenac. ${ }^{38} \mathrm{~A}$ rapid change in prescribing patterns was observed with a marked decrease in diclofenac prescribing with a corresponding increase for naproxen (figure 6).

\section{DISCUSSION}

This study demonstrates high adherence to the Wise List recommendations in the Stockholm Healthcare Region. The overall adherence rate increased steadily over time, but with variations between therapeutic areas. Additionally, the number of recommended core substances has been kept stable (around 200 substances) for the 15 years since the introduction of the Wise List, despite the number of substances with market authorisation in Sweden increasing from 1235 to 1554 in the same time period. ${ }^{39}$ A limited number of recommendations is critical to make it feasible for prescribers to choose the best therapies for their patients, keeping knowledge up to date among prescribers about the clinical pharmacology and pharmacotherapeutic characteristics of each recommended medicine. ${ }^{89} 15$
Figure 4 Prescribing pattern for proton pump inhibitors (PPI) in Stockholm Healthcare Region between 2002 and 2015 showing all PPI prescriptions dispensed to the inhabitants in the region each year. The letter ' $R$ ' signifies that the drug was a core recommendation in the Wise List that year. DDD/TID, defined daily dose/1000 inhabitants/day.

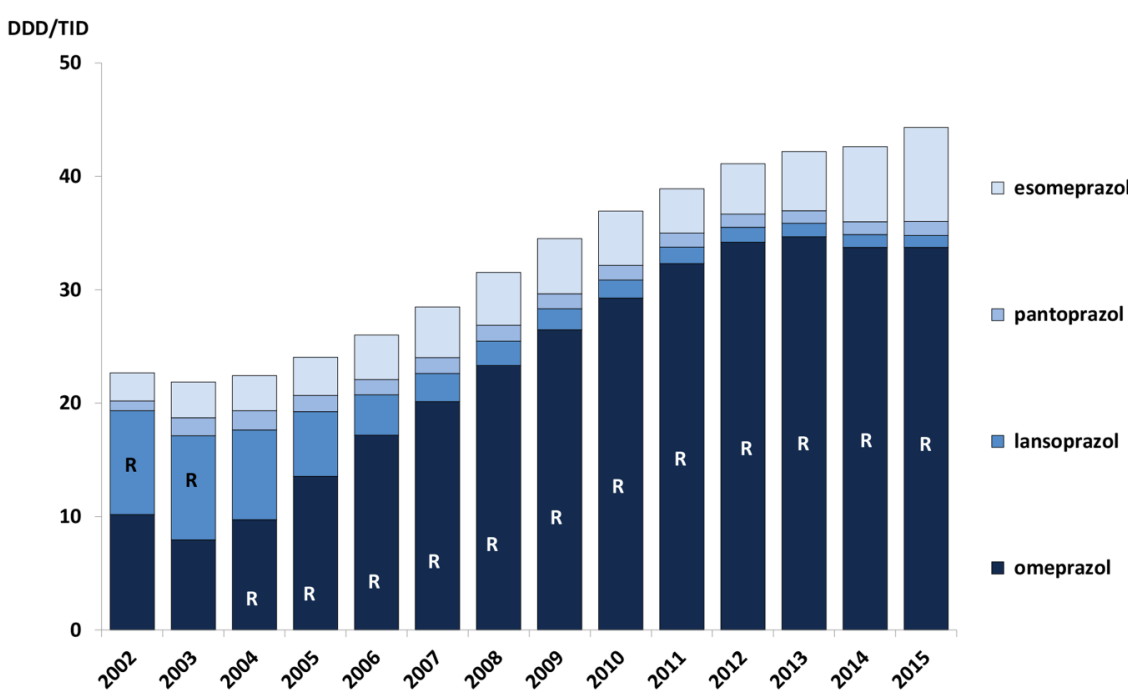


Figure 5 Prescribing pattern for selective serotonin receptor uptake inhibitors (SSRIs) and serotonin-norepinephrine reuptake inhibitors (SNRIs) in Stockholm Healthcare Region between 2002 and 2015 showing all SSRI and SNRI prescriptions dispensed to the inhabitants in the region each year. The letter ' $R$ ' signifies that the drug was a core recommendation in the Wise List that year. ('Others' includes duloxetine, fluoxetine, paroxetine). DDD/TID, defined daily dose/1000 inhabitants/day.

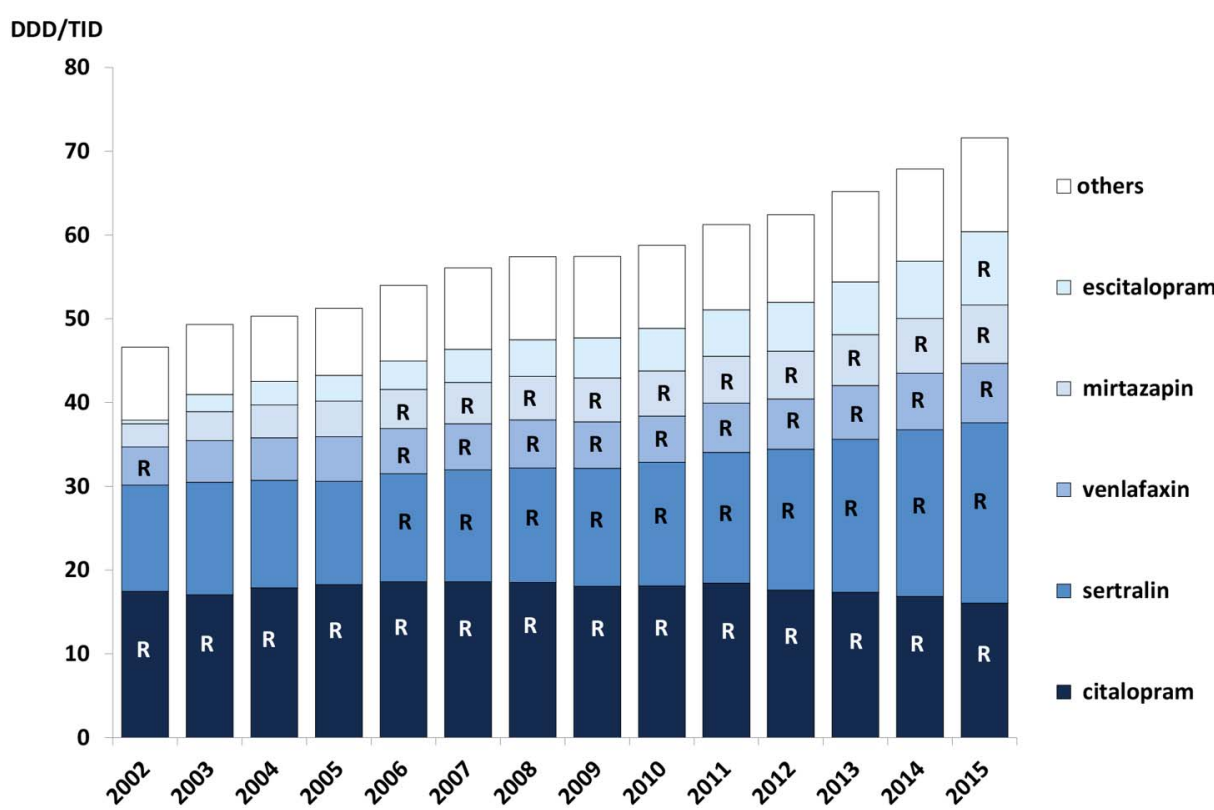

High adherence to the Wise List recommendations was seen across all therapeutic areas in primary and hospital care. There could be several reasons for this. We consider that the transparent development process of recommendations involving respected experts and clinicians within different therapeutic areas and strict criteria for handling potential conflicts of interests are essential for the high success rates to recommendations. ${ }^{15} 40$ Sound and trusted evidence-based guidelines in combination with a communication strategy consisting of a branding and marketing strategy for prescribers and the public, integrated with a programme for continuous medical education, are major factors for successful adherence to DTC recommendations. In Stockholm, this communication strategy and the continuous medical education programme is an ongoing, continuously evolving important part of the Wise List strategy. ${ }^{18}$ The branding and marketing strategy is based on principles of social marketing. Core values of the brand Wise List have been defined as a shortlist of the best medicines, set up by respected experts and clinicians, for the best treatment of the most common diseases. This is in contrast to the marketing material provided by pharmaceutical industry. The Wise List has been promoted to prescribers and patients by traditional marketing methods such as advertisements in print, direct mail marketing like postcards, brochures, letters and fliers and at oral presentations among stakeholders. The core value of the product has been consistent over the years and so also the key message in the marketing campaigns. ${ }^{1415} 18$ Prescriber ownership of the strategy has strengthened the Wise List work in developing and
Figure 6 Prescribing pattern for COX inhibitors in Stockholm Healthcare Region between 2002 and 2015 showing all COX inhibitor prescriptions dispensed to the inhabitants in the region each year. The letter ' $R$ ' signifies that the drug was a core recommendation in the Wise List that year. ('Others' includes aceclofenac, dexibuprofen, phenylbutazone, indomethacin, ketorolac, lornoxicam, meloxicam, nabumetone, piroxicam, sulindac, tenoxicam). DDD/TID, defined daily dose/1000 inhabitants/day.

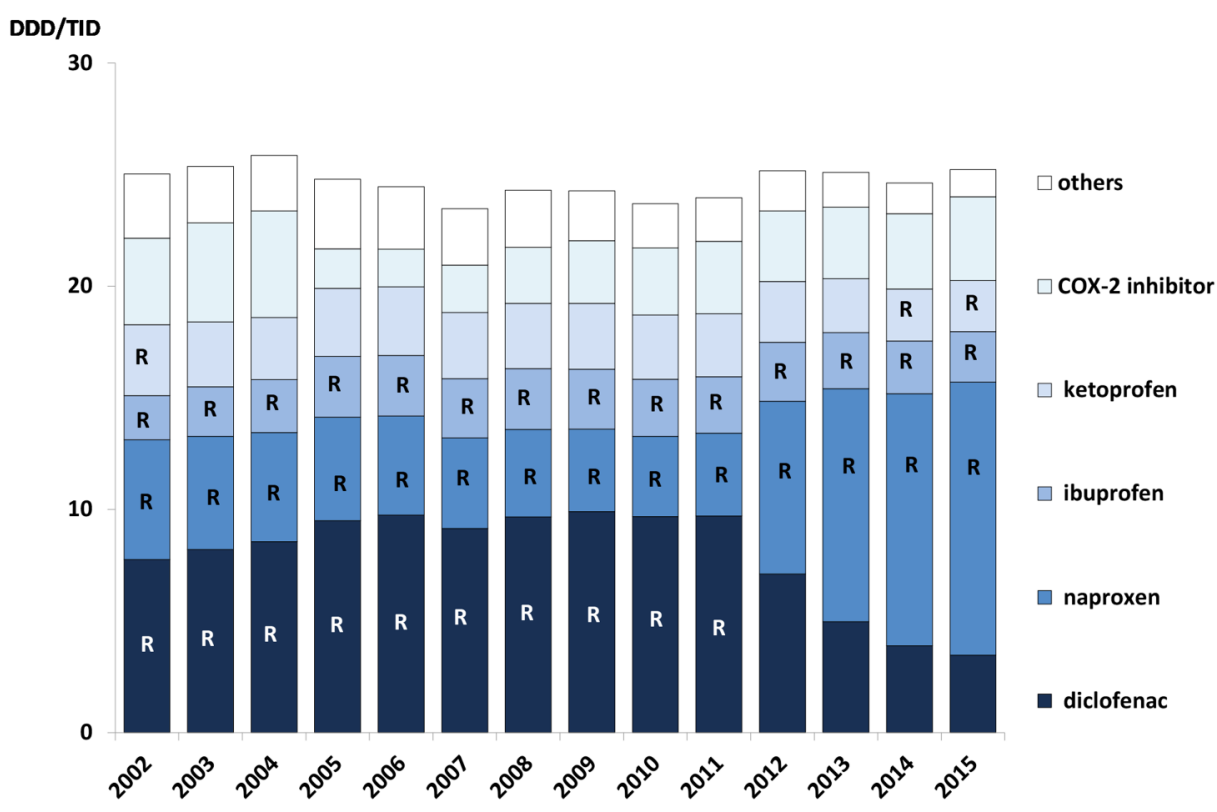


adopting state-of-the-art recommendations. ${ }^{11-13} \quad 15 \quad 16$ Multifaceted interventions, academic detailing and reminders have all been found to be effective. ${ }^{16} 4142$

Financial incentives were introduced in Stockholm healthcare region in $2008^{14}$ and have also been shown to contribute to the high adherence. ${ }^{35}$ Originally, these incentives were introduced in primary care where PHCs received a small bonus linked to their adherence to the Wise List if the adherence was more than $80 \%$ and if they reflected on their prescribing patterns in a "quality report'. ${ }^{35}$ A higher target has not been set, as complete adherence is not considered suitable. This is because the Wise List does not include all possible treatment strategies, for example, complicated cases, patients with allergies to medicines or cases with potential drug-drug interactions. Physicians should have the possibility of using their clinical judgement and prescribe a substance not included on the Wise List if this is better for the patients. Therefore, complete adherence is neither wanted nor aimed for. Since 2008 core Wise List medicines (about 200) are free of charge for all hospitals, whereas they have to fund $50 \%$ of the cost of all other prescribed medicines. Previously, the healthcare region covered all costs for prescriptions across hospitals and healthcare institutions centrally.

Our findings from the specific therapeutic areas demonstrate that the prescribers switched substances within a therapeutic area and reduced undertreatment in accordance with the Wise List and Wise pieces of advice. However, the list has not been successful in reducing overtreatment. The failure in reducing PPI use is in concordance with other European countries where prescribing of PPI has also increased several-fold. ${ }^{32}$ In contrast, there was a marked switch in COX inhibitor prescriptions from diclofenac to naproxen after a change of recommendations in the 2012 Wise List edition. An important explanation for the difference in adherence between these therapeutic areas may be the fact that using omeprazole has no clear medical disadvantage. The reason for switching from diclofenac to naproxen was accumulated evidence showing increased risk of cardiovascular disease with diclofenac, ${ }^{38}$ which was clearly accepted by clinicians. Similar to the findings for COX inhibitors, the prescribers followed the recommendations for statins and SSRI/SNRI to a high degree and the prescribing of nonrecommended escitalopram was low, despite high marketing pressure similar to that of esomeprazole. ${ }^{37}$ This marketing pressure from the pharmaceutical industry could have contributed to the failure in reducing PPI prescriptions, but despite increasing numbers of prescriptions, the vast majority remained omeprazole, as recommended by the Wise List. The adherence to the recommendation to use simvastatin instead of atorvastatin or rosuvastatin resulted in substantial economical savings for the Stockholm Health Care Region in contrast to other countries where rosuvastatin was the most prescribed statin. ${ }^{43}$ To illustrate this, if just $10 \%$ of the simvastatin DDD had been replaced by rosuvastatin in 2008 , this would have increased costs by 14.4 million SEK ( 1 SEK $\sim 0.1 €$ in 2008). This is similar to a Canadian study of publically funded outpatient medicines where implementing harmonised prescribing recommendations could save pharmaceutical cost. ${ }^{44}$ Regional differences in medicine costs within the Medicare system in the USA have been shown to depend on the medicines selected for the formulary. ${ }^{45}$

Although we can relate prescribing data to the content of the Wise List and the Wise pieces of advice, without a control group, we cannot know whether the seemingly high adherence is in fact due to a causal relationship between these factors. However, a major strength of the study is that we have data for a whole region, including all prescriptions from all care providers.

New niche medicines, soaring medicine costs and limited budgets pose new challenges to healthcare systems globally. Furthermore, the large number of new expensive biological medicines in pipeline has highlighted the importance of priority setting and development of methods to monitor the adherence to the recommendations, ${ }^{46}$ and high-quality evidence-based recommendations to prescribers, such as the Wise List, become increasingly important. This is in line with the Lancet's Commission on Essential Medicines Policies' recommendations for achieving Sustainable Development Goal 3.8 for universal access to safe, effective, quality and affordable essential medicines and vaccines. ${ }^{47}$ The Wise List already contains recommendations for some new expensive biological medicines, for example, TNF inhibitors for use in inflammatory bowel disease and rheumatological diseases. In our opinion, it is of critical importance that trusted recommendations and introduction protocols are developed for the use of new expensive medicines. A DTC/Wise List with focus on and with recommendations for specialised healthcare is necessary to ensure cost-effective and egalitarian use of medicines in the future. In fact, a recent study of ours demonstrated that the most important factor influencing the use of anticoagulants, warfarin or a New Oral Anticoagulants, in Stockholm during the past 5 years, was whether the substance was included as a Wise List recommendation. ${ }^{48}$ New multifaceted methods for safe and successful evidence-based introduction of medicines must be developed. This will be a major challenge for the future but could build on components in the Wise List concept that has led to high adherence to recommendations sustained for 15 years.

\section{Author affiliations}

${ }^{1}$ Division of Clinical Pharmacology, Department of Laboratory Medicine, Karolinska Institutet, Stockholm, Sweden

${ }^{2}$ Department of Clinical Pharmacology, Karolinska University Hospital, Stockholm, Sweden

${ }^{3}$ Stockholm Drug and Therapeutics Committee, Public Healthcare Services Committee, Stockholm, Sweden

${ }^{4}$ Medical Management Centre, Department of Learning, Informatics, Management and Ethics (LIME), Karolinska Institutet, Stockholm, Sweden ${ }^{5}$ Department of Quality and Development, Södersjukhuset, Stockholm, Sweden 
${ }^{6}$ Public Healthcare Services Committee, Stockholm, Sweden

${ }^{7}$ Department of Clinical Science and Education, Södersjukhuset, Internal Medicine, Karolinska Institutet, Stockholm, Sweden

${ }^{8}$ Department of Medicine Solna, Karolinska Institutet, Stockholm, Sweden

Acknowledgements The authors would like to thank Stockholm Healthcare Region for providing time for experts to evaluate the data making completion of this study possible.

Collaborators Tareq Alsaody, Peter Aspelin, Peter Bárány, Harry Beitner Johan Bratt, Torkel B Brismar, Marja-Liisa Dahl, Ulrika Dahnell, Paulina Dalemo, Christine Fransson, Stina Fransson Sellgren, Jan Hasselström, Roger Henriksson, Rose Marie Hallin, Paul Hjemdahl, Margareta Holmström, Charlotte Höybye, Thomas Kahan, Inga Klarin, Angelica Lindén Hirschberg, Synnöve Lindemalm, Mikael Lördal, Mussie Msghina, Ricard Nergårdh, Christer Norman, Åke Örtqvist, Peter Persson, Magnus Röjvall, Michael Runold, Carl-Olav Stiller, Marie Almvik (Sundström), Leif Tallstedt, Inga Tjäder, Mia von Euler and Rumiana Zlatewa are either the present member of Stockholm DTC or chairing 1 of the 21 expert panels of Stockholm DTC. None of the authors or collaborators listed here has received any salary or economic support for the research presented in this work.

Contributors JE contributed to the conception and design of the study analysis and interpretation of the data, drafted and revised the manuscript. LLG contributed to the conception and design of the study, analysis and interpretation of the data, and revised the manuscript. KA contributed to data acquisition, analysis and interpretation, and revised the manuscript. PB-R contributed to data analysis and interpretation, and revised the manuscript. BW contributed to the conception and design of the study, data acquisition, analysis and interpretation of the data, and revised the manuscript. MJ contributed to data analysis and interpretation, and revised the manuscript. $\mathrm{MJ}-\mathrm{H}$ contributed to the data acquisition, analysis and interpretation of the data, and revised the manuscript. REM contributed to the conception and design of the study, analysis and interpretation of the data, and revised the manuscript. M-LO contributed to the conception and design of the study, analysis and interpretation of the data, and revised the manuscript. GL contributed to data analysis and interpretation, and revised the manuscript. EA-K contributed to the conception and design of the study, analysis and interpretation of the data, and revised the manuscript. All authors critically revised and approved the final manuscript.

Funding This study was in part supported by grants from Karolinska Institutet, Stockholm, Sweden.

Competing interests JE is the member of an expert panel of the Stockholm DTC since 2013. KA, PB-R, MJ-H, MJ, M-LO and BW are employed by Stockholm Healthcare Region that finances the Drug and Therapeutics Committee (DTC) issuing the 'Wise List' in Stockholm. EA-K served as the chair-woman of Stockholm DTC 2010-2016, LLG as the chairman 20002009 and GL is the chair-woman since 2016 and REM deputy chairman since 2016 .

Provenance and peer review Not commissioned; externally peer reviewed.

Data sharing statement We have used routinely available prescribing data for a selected group of therapeutic classes. More analyses can be made for these medicines as well as for other medicines prescribed in Sweden.

Open Access This is an Open Access article distributed in accordance with the Creative Commons Attribution Non Commercial (CC BY-NC 4.0) license, which permits others to distribute, remix, adapt, build upon this work noncommercially, and license their derivative works on different terms, provided the original work is properly cited and the use is non-commercial. See: http:// creativecommons.org/licenses/by-nc/4.0/

\section{REFERENCES}

1. Bergman U, Wiholm BE. Drug-related problems causing admission to a medical clinic. Eur J Clin Pharmacol 1981;20:193-200.

2. Davies EC, Green CF, Taylor S, et al. Adverse drug reactions in hospital in-patients: a prospective analysis of 3695 patient-episodes. PLOS ONE 2009;4:e4439.
3. Mölstad S, Erntell M, Hanberger $\mathrm{H}$, et al. Sustained reduction of antibiotic use and low bacterial resistance: 10-year follow-up of the Swedish Strama programme. Lancet Infect Dis 2008;8:125-32.

4. WHO. The rational use of drugs-report of the conference of experts Nairobi, 25-29 November 1985. Geneva, Switzerland: World Health Organization, 1987. http://appswhoint/medicinedocs/documents/ s17054e/s17054epdf

5. McGinn D, Godman B, Lonsdale J, et al. Initiatives to enhance the quality and efficiency of statin and PPI prescribing in the UK: impact and implications. Expert Rev Pharmacoecon Outcomes Res 2010;10:73-85.

6. Norman C, Zarrinkoub R, Hasselström J, et al. Potential savings without compromising the quality of care. Int $J$ Clin Pract 2009;63:1320-6.

7. Fijn R, Brouwers JR, Knaap RJ, et al. Drug and Therapeutics (D \& T) committees in Dutch hospitals: a nation-wide survey of structure, activities, and drug selection procedures. Br J Clin Pharmacol 1999;48:239-46.

8. Sjöqvist F, Bergman U, Dahl M, et al. Drug and therapeutics committees: a Swedish experience. WHO Drug Information 2002;16:207.

9. Birkett D, Brøsen K, Cascorbi I, et al. Clinical pharmacology in research, teaching and health care: considerations by IUPHAR, the International Union of Basic and Clinical Pharmacology. Basic Clin Pharmacol Toxicol 2010;107:531-59.

10. WHO. The Selection of Essential Drugs: Report of a WHO Expert Committee. Technical Report Series no 615. Geneva, Switzerland: World Health Organization, 1977.

11. Schiff GD, Galanter WL, Duhig J, et al. A prescription for improving drug formulary decision making. PLoS Med 2012;9:1-7.

12. Grol R, Grimshaw J. From best evidence to best practice: effective implementation of change in patients' care. Lancet 2003;362:1225-30.

13. Grol R. Successes and failures in the implementation of evidence-based guidelines for clinical practice. Med Care 2001;39(8 Suppl 2):II46-54.

14. Godman B, Wettermark B, Hoffmann M, et al. Multifaceted national and regional drug reforms and initiatives in ambulatory care in Sweden: global relevance. Expert Rev Pharmacoecon Outcomes Res 2009:9:65-83.

15. Gustafsson LL, Wettermark B, Godman B, et al. The 'wise list'-a comprehensive concept to select, communicate and achieve adherence to recommendations of essential drugs in ambulatory care in Stockholm. Basic Clin Pharmacol Toxicol 2011:108:224-33.

16. Grimshaw JM, Thomas RE, MacLennan G, et al. Effectiveness and efficiency of guideline dissemination and implementation strategies. Health Technol Assess 2004;8:iii-iv, 1-72.

17. Grol R, Dalhuijsen J, Thomas S, et al. Attributes of clinical guidelines that influence use of guidelines in general practice: observational study. BMJ 1998;317:858-61.

18. Bjorkhem-Bergman L, Andersen-Karlsson E, Laing R, et al. Interface management of pharmacotherapy. Joint hospital and primary care drug recommendations. Eur J Clin Pharmacol 2013;69(Suppl 1):73-8.

19. Wettermark B, Haglund K, Gustafsson LL, et al. A study of adherence to drug recommendations by providing feedback of outpatient prescribing patterns to hospital specialists. Pharmacoepidemiol Drug Saf 2005;14:579-88.

20. The Stockholm Drug and Therapeutics Committee. The Wise List 2015 in English. Stockholm, Sweden: Stockholm Healthcare Region, 2015. http://wwwjanusinfose/In-English/The-Wise-List-2015-inEnglish/.

21. Kumar Kakkar A, Dahiya N. The evolving drug development landscape: from blockbusters to niche busters in the orphan drug space. Drug Dev Res 2014;75:231-4.

22. Yeh JS, Franklin JM, Avorn J, et al. Association of industry payments to physicians with the prescribing of brand-name Statins in Massachusetts. JAMA Intern Med 2016;176:763-8.

23. Lieb K, Scheurich A. Contact between doctors and the pharmaceutical industry, their perceptions, and the effects on prescribing habits. PLOS ONE 2014;9:e110130.

24. Abbasi K, Smith R. No more free lunches. BMJ 2003;326:1155-6.

25. Stockholm County Counsil DTC. Jävspolicy för läkemedelskommittéorganisationen i Stockholms läns landsting (SLL). 2011. http://www.janusinfo.se/Global/SLK/javspolicy_slk_ 2011_2.pdf2016.

26. WHO. WHO model list of essential medicines-19th list Geneva Switzerland: World Health Organization, 2015. http://www.who.int/ medicines/publications/essentialmedicines/en/

27. Anell A. The public-private pendulum-patient choice and equity in Sweden. N Engl J Med 2015;372:1-4. 
28. WHO. WHO Collaborating Centre for Drug Statistics Methodology, Guidelines for ATC classification and DDD assignment, 2015. Oslo: World Health Organization, 2014.

29. Wettermark B, Hammar N, Fored CM, et al. The new Swedish Prescribed Drug Register-opportunities for pharmacoepidemiological research and experience from the first six months. Pharmacoepidemiol Drug Saf 2007;16:726-35.

30. Vlahović-Palcevski V, Gantumur M, Radosević N, et al. Coping with changes in the defined daily dose in a longitudinal drug consumption database. Pharm World Sci 2010;32:125-9.

31. Andersson K, Bergström G, Petzold MG, et al. Impact of a generic substitution reform on patients' and society's expenditure for pharmaceuticals. Health Policy 2007;81:376-84.

32. Godman B, Shrank W, Andersen M, et al. Comparing policies to enhance prescribing efficiency in Europe through increasing generic utilization: changes seen and global implications. Expert Rev Pharmacoecon Outcomes Res 2010;10:707-22.

33. Godman B, Malmstrom RE, Diogene E, et al. Are new models needed to optimize the utilization of new medicines to sustain healthcare systems? Expert Rev Clin Pharmacol 2015;8:77-94.

34. Bergman U, Popa C, Tomson $Y$, et al. Drug utilization $90 \%-a$ simple method for assessing the quality of drug prescribing. Eur J Clin Pharmacol 1998;54:113-18.

35. Wettermark B, Pehrsson A, Juhasz-Haverinen $\mathrm{M}$, et al. Financial incentives linked to self-assessment of prescribing patterns: a new approach for quality improvement of drug prescribing in primary care. Qual Prim Care 2009;17:179-89.

36. Hjemdahl $\mathrm{P}$, Allhammar A, Heaton $\mathrm{C}$, et al. [SBU should investigate what is an evidence-based and cost-effective use of statins]. Lakartidningen 2009;106:1992-4.

37. Gellad WF, Choi P, Mizah M, et al. Assessing the chiral switch approval and use of single-enantiomer drugs, 2001 to 2011. Am J Manag Care 2014;20:e90-7.
38. Fosbøl EL, Folke F, Jacobsen S, et al. Cause-specific cardiovascular risk associated with nonsteroidal antiinflammatory drugs among healthy individuals. Circ Cardiovasc Qual Outcomes 2010;3:395-405.

39. Swedish Medical Products Agency. National Substance Register for Medicinal Products (NSL). 2016. http://nsl.mpa.se/index_english. htm2016

40. Stammen LA, Stalmeijer RE, Paternotte E, et al. Training physicians to provide high-value, cost-conscious care: a systematic review. JAMA 2015;314:2384-400.

41. Dreischulte T, Donnan P, Grant A, et al. Safer prescribing-a trial of education, informatics, and financial incentives. N Engl J Med 2016;374:1053-64.

42. Oxman AD, Thomson MA, Davis DA, et al. No magic bullets: a systematic review of 102 trials of interventions to improve professional practice. CMAJ 1995;153:1423-31.

43. Wolfe S. Rosuvastatin: winner in the statin wars, patients' health notwithstanding. BMJ 2015;350:h1388.

44. Lapointe-Shaw L, Fischer HD, Newman A, et al. Potential savings of harmonising hospital and community formularies for chronic disease medications initiated in hospital. PLOS ONE 2012;7:e39737.

45. Donohue JM, Morden NE, Gellad WF, et al. Sources of regional variation in Medicare Part D drug spending. $N$ Engl $J$ Med 2012;366:530-8.

46. Wettermark B, Persson ME, Wilking N, et al. Forecasting drug utilization and expenditure in a metropolitan health region. $B M C$ Health Serv Res 2010;10:128.

47. Wirtz VJ, Hogerzeil HV, Gray AL, et al. Essential medicines for universal health coverage. Lancet 2017;389:403-76.

48. Komen J, Forslund T, Hjemdahl P, et al. Effects of policy interventions on the introduction of novel oral anticoagulants in Stockholm: an interrupted time series analysis. Br J Clin Pharmacol 2017;83:642-52. 